\title{
Should access to transcatheter aortic valve replacement be limited to high-volume surgical centers?
}

Robert M. Sade, MD

See related articles by Joseph E. Bavaria on pages 1441-3 and Philip Green et al on pages 1444-5.

Joseph Bavaria and Allan Schwartz participated in a debate held at the Postgraduate Course of the American Association for Thoracic Surgery 2012 Annual Meeting, presenting opposing positions on the question of whether transcatheter aortic valve replacement should be limited to high-volume centers. They and coauthors present their arguments in this issue of the Journal. ${ }^{1,2}$ The discussion is a new incarnation of the long-standing volume-outcome relationship debate, placed this time in the context of a new technology that is shared by cardiac surgeons and interventional cardiologists. Bavaria presents a great deal of data based on published literature over the last 3 decades; these data generally show that larger volume programs and individual surgeons are associated with better outcomes in terms of mortality and morbidity, with a few exceptions. Green and colleagues present arguments based on recent studies that show no volume-outcome associations and a number of other arguments suggesting that limiting access to transcatheter aortic valve replacement is not a good idea.

Several important issues related to the volume-outcomes ongoing debate are not addressed by either side of this discussion, however. These are related to excellence, wellcontrolled studies, and moving targets.

\section{EXCELLENCE}

All physicians aspire to be the best that they can be and to provide every patient with the highest quality care. These are aspirations, however, not requirements. The requirement for surgeons is not perfection and is not even excellence-it is competence. ${ }^{3}$ Certification and Maintenance of Certification in a medical specialty are measures of

\footnotetext{
From the Division of Cardiothoracic Surgery, Department of Surgery, Institute of Human Values in Health Care, Medical University of South Carolina, Charleston, SC. Disclosures: Author has nothing to disclose with regard to commercial support. Read at the 92nd Annual Meeting of The American Association for Thoracic Surgery, San Francisco, California, April 28-May 2, 2012.

Received for publication Feb 25, 2013; accepted for publication Feb 27, 2013; available ahead of print March 25, 2013.

Address for reprints: Robert M. Sade, MD, Department of Surgery, Medical University of South Carolina, 25 Courtenay Drive, Suite 7028, MSC 295, Charleston, SC 29425 (E-mail: sader@musc.edu).

J Thorac Cardiovasc Surg 2013;145:1439-40

$0022-5223 / \$ 36.00$

Copyright (c) 2013 by The American Association for Thoracic Surgery

http://dx.doi.org/10.1016/j.jtcvs.2013.02.058
}

competence; the programmatic requirements of the various specialty boards are the 6 core competencies that are well known to us ${ }^{4}$ - they have never been designated the 6 core excellences. Requiring that every patient be sent to centers associated with the best outcomes is ethically questionable, and making such a requirement a matter of policy seems overreaching. If a surgeon is competent, his or her results may not measure up to those of a master surgeon, but that should not in itself justify depriving potential patients of his or her services.

\section{WELL-CONTROLLED STUDIES}

Existing studies of the volume-outcome association suffer from the biases that plague all retrospective studies. For example, wide variation in study methodology makes metaanalysis of the volume-outcome relation impossible and is probably responsible for much of the great variation in conclusions reached by those studies. ${ }^{5}$ Moreover, the data in most studies come from administrative databases, which are notoriously unreliable regarding their clinical accuracy, and are not risk adjusted. ${ }^{6}$ These important flaws make the conclusions of such studies unreliable grounds for making policy decisions that might make referral lines unreasonably rigid. The need is for studies that are designed for prospective collection of clinically accurate risk-adjusted data. Such studies seem unlikely to take place in the near future.

\section{MOVING TARGETS}

The studies of volume-outcome associations that have been done to date are snapshots, that is, they measure relations between surgeon or center volume compared with outcomes over a specified time period. But it might be the case that those relations vary substantially over time. Some small centers have become bigger centers over several years by demonstrating improved results. Many examples of this could be cited, but in my own institution, the volume of aortic aneurysm/dissection surgery has tripled since Dr John Ikonomidis joined our faculty immediately after finishing his training 12 years ago. The volume increase has been a result of his interest in such surgery and his excellent results. This growth would not have occurred if aortic surgery had been regionalized to high-volume centers in the late 1990s. Surgical volumes and outcomes are moving targets. It would be helpful to know how many large-volume programs have become smaller and low-volume programs larger over 1 or 2 decades, and how these changes correlated with outcomes. Such a study has not yet been done. 


\section{CONCLUSIONS}

The volume-outcome controversy is likely to continue in the future, partly in an effort to find ways to optimize outcomes for patients and perhaps partly as a means for large programs to increase market share. There are good arguments to be made on both sides of this question, and Bavaria and Green and colleagues have presented some of them. This editorial attempts to fill in some of the gaps in their presentations.

\section{References}

1. Bavaria JE. Access to transcatheter aortic valve replacement should be limited to high volume centers. J Thorac Cardiovasc Surg. 2013;145:1441-3.
2. Green P, Rosner GF. Leon MB, Schwartz A. Access to TAVR should not be limited to high volume surgical centers. J Thorac Cardiovasc Surg. 2013;145:1444-5.

3. Council on Ethical and Judicial Affairs. Principles of Medical Ethics, Principle I. Code of Medical Ethics of the American Medical Association, Current Opinions with Annotations. 2012-2013 ed. Chicago, IL: American Medical Association; 2012:xx-xxvi.

4. American Board of Medical Specialties. MOC Competencies and Criteria. Available at: http://www.abms.org/maintenance_of_certification/MOC_competencies. aspx. Accessed February 5, 2013.

5. Halm EA, Lee C, Chassin MR. Is volume related to outcome in health care? A systematic review and methodologic critique of the literature. Ann Intern Med. 2002; 137:511-20.

6. Cerfolio RJ, Jacobs JP. Sade RM. The ethics of transparency: publication of cardiothoracic surgical outcomes in the lay press. Ann Thorac Surg. 2009;87: 679-86. 